Running head: Lexical Interference in Semantic Processing

Lexical Interference in Semantic Processing of Simple Words:

Implications for Brand Names

Published in Psychology \& Marketing (2005), 22 (January), pp. 51-69.

Judith E. Hennessey

California State University, Northridge

Theodore S. Bell

California State University, Los Angeles

Robert J. Kwortnik

Cornell University 


\begin{abstract}
This study provides evidence for a Stroop-like interference effect in word recognition. Based on phonologic and semantic properties of simple words, participants who performed a same/different word-recognition task exhibited a significant response latency increase when word pairs (e.g., POLL, ROD) featured a comparison word (POLL) that was a homonym of a synonym (pole) of the target word (ROD). These results support a parallel-processing framework of lexical decision making, in which activation of the pathways to word recognition may occur at different levels automatically and in parallel. A subset of simple words that are also brand names was examined and exhibited this same interference. Implications for word recognition theory and practical implications for strategic marketing are discussed.
\end{abstract}




\section{Lexical Interference in Semantic Processing of Simple Words: Implications for Brand Names}

Some of the best-known brand names are simple, common words, for example: Aim, Raid, Gap, Sure, Glad, and Tide. These simple names possess characteristics that Kotler and Armstrong (2004) propose are desirable for brands: these words suggest something about the product and its benefits; they are easy to say, recognize, and recall; and, they can be registered as trademarks and legally protected. However, because these simple brand names are drawn from common lexicon, they are not especially distinctive and can take on multiple meanings in addition to the intended identity. For example, Gap is a clothing/lifestyle brand, but also a space or break; in contrast, names such as Nike and Budweiser possess unique, brand-only meanings.

Recent research in marketing has shown that phonetic properties of brand names can impact consumer judgment (Yorkston \& Menon, 2004). Factors that influence brand name processing and interference are issues for strategic brand management (Keller, 1998; Zaichkowsky, 1995) and brand protection (Simonson, 1994; Taylor \& Walsh, 2002). Confusion and interference have been the source of research in the word recognition literature. Researchers in both psychology and marketing have established the influence of many factors - graphemic, phonemic, orthographic, phonologic, semantic, syntactic, and others - contributing to word recognition. Debate continues over the form of the lexical process; specifically, how the interaction of word properties and task effects can alter the pathways to and from memory and inhibit or facilitate lexical processing.

This study examines the interaction of phonologic-to-semantic associations between words and patterns of lexical decision-making. Specifically, we test for a previously undetected lexical version of the classic Stroop effect (Stroop, 1935). The Stroop effect is a processing interference created when a person is asked to classify a stimulus perceptually (e.g., by color) while semantic processing suggests an alternate meaning-based classification (e.g., the word "red" written in blue ink) or vice versa. In the present study it is proposed that a similar processing effect can be created when a person is asked to classify words semantically, while phonological (speech sound) activation suggests an alternate classification. Spoken word recognition studies have shown lexical confusion is based partly in acoustic-phonetic similarities (Bell \& Wilson, 2001; Goldinger, Luce \& Pisoni, 1989).

The next section of this paper offers a brief review of models of lexical access and their interactive connections with semantic word processing. Based on this research, we develop an experimental task and set of hypotheses that predict lexical interference in word processing due to the interaction of phonologic and semantic properties of word pairs. Results from these experiments are then presented and examined in the context of word-recognition theory. The paper closes with a discussion of implications for marketing practice, specifically the development and protection of simple brand names.

\section{Word Recognition Theory}


In general, research on word recognition suggests that lexical processing occurs via two primary paths: direct access (spelling to identification) and indirect access (spelling to sound representation to identification) (Coltheart, Rastle, Langdon \& Zeigler, 2001; Van Orden, Johnston \& Hale, 1988). However, task factors, semantic processing, individual differences in processing styles, and other effects complicate word recognition. These influences and models of lexical access are discussed below.

\section{Indirect Lexical Access}

Evidence of lexical pathways is primarily based on the classic phonological-coding route, whereby a stimulus word (e.g., hare), activates an orthographic (spelling) representation, which in turn activates a phonological representation that leads to a lexical representation (Van Orden et al, 1988). Arguments for indirect access in lexical processing take into account the nature of the task of word identification. These studies suggest that the intermediate step of converting the visual stimulus into a sound stimulus may be necessary to gain access to word meaning stored in memory. For example, Hardyck and Petrinovitch (1970) showed that this intermediate step is often revealed as a task becomes more difficult or stressful, such as reading a challenging word. Studies involving children support the use of a phonologic code, such as sub-vocalization, to facilitate word recognition, faster reading, and more accurate comprehension (see Wagner \& Torgeson, 1987). Similarly, in tasks where homonyms were substituted for the correct words, readers were found to say a sentence made sense if it "sounded" correct (Doctor \& Coltheart, 1980). Coltheart, Laxon, Rickard, and Elton (1988) reported a significantly higher level of false positives for people who read sentences that were phonologically acceptable, but semantically unacceptable (e.g., The girl through the ball.). The authors described these errors as the result of "phonological recoding" which influenced meaning and access to meaning.

\section{Direct Lexical Access}

Several studies, however, also support a simple direct-access route for lexical decisionmaking. For example, homonym studies reviewed by Bradshaw (1975) note that orthographic properties of sound-alike words (e.g., PAIR and PARE) automatically represent different meanings based solely on a visual stimulus. Bradshaw and Nettleton (1974) showed that the pronunciation of the first word in spelled alike/sound different word pairs (e.g., horse-worse) interferes with the processing of the second word, though this interference disappears with the silent reading of the first word. Seidenberg and McClelland (1989) developed a simple computational model of word recognition that features a learning algorithm to represent this direct, orthographic coding without phonological feedback. Their model is notable for conceptualizing lexical processing as a single-route, scaled system that is a function of practice (learning) with orthographic rules.

\section{Direct and Indirect Lexical Access}

Baron and Strawson (1976) assumed ease of processing was reflected in reading speed and showed that readers of two types, visual/spelling dominant and sound dominant, exist. Visual/spelling-to-sound readers had more trouble reading words like "sword" than "sweet." The "sw" consonant blend is "regular" and therefore "easy" to process in "sweet" but less regular and 
therefore more difficult to process in "sword." With other readers, reading speed between such words did not vary. Naish (1980) found gender effects in lexical processing, specifically, differences in the speed of a sorting task for pseudo-homophone (sound-alike non-word) controls, which suggested that men and women apply different reading strategies. Martin (1978) proposed a dual-encoding hypothesis illustrating the use of either a visual or sound route in word recognition. Which route will dominate depends on reading skill, the nature of the material, and contextual factors, such as stress or distraction.

In a series of four experiments Humphreys, Everett and Taylor (1982) provide further support for dual-encoding lexical pathways. In their study primes preceding target words were manipulated. A prime was either a homonym of a target word (maid-MADE), graphemically similar to the target word (mark-MAID), or unrelated to the target word (maid-SHIP). Both word and non-word primes were examined. When primes were homonyms of target words in the word recognition task, facilitation was greatest. However, phonetic facilitation was not found when primes were non-word homophones. Although graphemic facilitation was not as strong as phonetic facilitation when primes were words, graphemic facilitation was enhanced by the extent of graphemic similarity (number and position of common letters) to target regardless of whether the primes were words or non-words. Further, the facilitation for phonetic primes that were words was equally strong for word pairs that followed regular English spelling-to-sound rules (days-DAZE) and those that did not (chute-SHOOT). The authors explain the enhanced facilitation of phonetic primes that could not be accounted for by graphemic similarity as evidence of automatic access to phonology. Further, the absence of facilitation when primes are non-words supports a lexical network mechanism. The finding that spelling-to-sound anomalies do not dampen the phonetic word primes (e.g. chute-shoot) further reinforces models of automatic phonetic access and a lexical mechanism in word recognition.

Van Orden (1987), however, questioned the necessity of the lexical mechanism offered by Humphreys et al (1982). Rather than a word recognition task, Van Orden used a categorization task. Participants were provided with a category (e.g. a part of the human body) and asked to classify a word as belonging or not belonging to the category. Words could be either correctly classified in the category (e.g. hair) or a homonym (hare) that could not fit the category. The author found significantly more classification errors for homonyms than unrelated words, and in a later study (Van Orden et al, 1988) for non-word homophones. Van Orden et al (1988) contended that the errors in classification were the result of spelling-to-phonetic classification interference rather than a lexical mechanism providing automatic access to phonology as suggested by Humphreys et al (1982). A lexical mechanism cannot account for the equivalent errors found for both word and non-word homophones.

\section{The Role of Semantic Knowledge in Lexical Processing}

One explanation for the Van Orden et al (1988) result is that the categorization context of the task encouraged semantic processing that swamped the priming effect of the real-word and non-word homophones of the target word. In other words, priming could be mediated by the semantic network, which in turn inhibits processing in the lexical network. McNamara and Healy (1988) were surprised to find just such a phenomenon in responses to mediated word pairs (e.g., LIGHT - DAMP). In their study, participants had to decide whether both letter strings were English words. Contrary to the authors' predictions, responses to mediated pairs were slow and less accurate than responses to control pairs (e.g., LIGHT - SING). The authors suggest that the 
word LIGHT may have activated a semantic associate such as "lamp," thus creating lexical interference due to similarity to the word, DAMP. In effect, the strength of the semantic pathway inhibited the phonological routing to lexical access $-\mathrm{a}$ finding that provides evidence for parallel processing in word recognition.

Word-recognition research also reveals the influence of semantic paths in lexical decision-making. For example, in the Humphreys et al (1982) study, word recognition was facilitated by homonym primes but not by non-word homophone primes. Since non-words would not exist as concepts in a lexical or semantic network, activation could not spread and thus could not facilitate activation of a target word. This finding suggests that sound alone is not sufficient to activate a broader network of words. Cohen, Dunbar, and McClelland (1990) presented a model of automatic and parallel-distributed processing that can simulate performance in the standard Stroop task, as well as many variants. The model requires that automaticity is continuous and subject to attentional control. As a parallel-distributed-processing framework, aspects of automaticity depend on the strength of a processing pathway, with strength increasing with training. Other researchers have found that semantic primes versus morphemic primes can control the extent of automaticity in processing words in the Stroop task specifically (Bauer \& Besner, 1997; Besner \& Stolz, 1999; Besner, Stolz \& Boultilier, 1997). Morphemic primes control attention to the visual form of the stimulus in these studies and are operationalized as a letter search task (find the letter D) that precedes a lexical decision. Attention focused on the letter search appears to suppress semantic processes and therefore the semantic interference seen in the Stroop task. However, Besner and MacNevin (2002) found that when the morphemic prime task was to identify the color of a letter rather than simply search for the letter, semantic processing was not suppressed and the Stroop task delay was observed. Semantic primes are related words presented with or before presentation of a target word (e.g. table-CHAIR). As discussed above, McNamara and Healy (1988) found that semantic primes generally facilitate the processing of a target word in a lexical decision task. Emergence of automaticity is dependent on the strength of processing required by the task relative to strengths of competing processes afforded by the task. The automaticity that produces the Stroop effect is dampened when the task focus from the prime limits processing as in the letter-search morphemic prime. As the task afforded more processing opportunity (find letter and identify color), the Stroop effect interference returned. Similarly, McNamara and Healy (1988) found that semantic primes may be helpful but can also provide competing responses (LIGHT-lamp-DAMP). The present study reflects this theoretical framework of a parallel activation of orthographic, phonetic, lexical and semantic processing systems. Automaticity is assumed to be continuous and controlled by task demand.

A number of word recognition models assume an interactive activation structure and process between orthographic and phonetic representations of words (Coltheart et al, 2001; Jacobs, Rey, Zeigler \& Grainger, 1998; McClelland \& Rumelhart, 1981). Borowsky, Owen and Fonos (1999) provided evidence that orthographic processing affects phonetic processing in word recognition tasks but phonetic processing did not affect orthographic processing. However, more recently, Borowsky and Owen (2003) found that phonetic processing could affect orthographic discriminations. These authors have suggested that semantic mediation and the relationship between the semantic system and the orthographic and phonetic system need to be explored as a potentially important extension of word recognition models.

In summary, current research supports a dual encoding, parallel distributed activation of orthographic, phonetic, lexical and semantic processes with possible interactive activation across 
processing systems. Activation of the processing system is automatic and continuous, but under attentional control.

\section{Implications for Brand Names}

Like powerful brand names (e.g., Coca-Cola, Disney, Nokia, and Toyota; see BusinessWeek, 2003), even simple-word names comprise a nexus of thoughts, feelings, and associations that imbue the brand with special meaning to consumers (Howard, Kerin \& Gengler, 2000; Jacoby \& Morrin, 1998; Keller 1993; Zaichkowsky 1995). Recent studies by Yorkston and Menon (2004) provided evidence that the phonetic structure of brand names can suggest attributes that are used in brand evaluation. For example, a brand can be gendered (in certain languages--e.g. French) by the phonetic properties of the article that precedes the brand name. Experimental results show a processing difficulty for participants and more negative evaluations of brands that suggest masculine attributes for feminine gendered product categories and vice versa. This process appears to be automatic and occurring without the participants' awareness. The automatic, unidirectional versus multidirectional activation of sub-lexical (orthographic and phonetic) and semantic levels of processing in word recognition will also be examined in this study.

\section{The Task and Hypotheses}

The present study was designed to test whether phonologic mediation in the lexical network could produce an inhibition of word comprehension as semantic and/or phonetic processes are activated by task variation (sound matching versus meaning matching), producing consistent or competing responses. The task was derived from (inspired by) a subset of the stimulus/task setup of the classic letter-naming/matching study of Posner and Keele (1967). The task in the present study was to respond to word pairs by matching on sound or meaning. Word pairs were homonyms (poll, POLE), synonyms (pole, ROD) or (apparently) unrelated words (poll, ROD). If one assumes that activation spreads in a parallel-distributed fashion and the automaticity in common word recognition depends, in part, on the strength of one activation process (e.g. phonetic) relative to the strengths of competing processes (e.g. semantic), then

$\mathrm{H} 1$ : A sound-matching task will take less time to respond to than a meaning-matching task.

H2: Homonyms will take less time to respond to than synonyms or unrelated word-pairs. This is because any word with different spellings and the same sound (homonyms) activates a consistent "different meaning" response in semantic matching and a consistent "same sound" response in sound matching (although the expected faster responses in the sound matching task should also affect synonym and unrelated word pairs).

H3: Sound-matching versus meaning-matching tasks will interact with word-pair type such that for sound-matching tasks, latency to respond "same" or "different" sound will not vary significantly between homonym, synonym and unrelated word-pair conditions because the task does not require semantic activation. However, for meaning-matching tasks there will be a significant difference between homonyms and both synonym and unrelated word-pair conditions. In this case, same sound implies different meanings for homonyms and semantic activation is not necessary. However, semantic activation is 
necessary to identify synonyms or unrelated words as having "same" or "different" meanings.

H4: $\quad$ For meaning matching tasks, when the comparison word in seemingly unrelated pairs has a homonym that is a synonym of the target word, a competing activation, generating a competing response, is activated automatically, thus resulting in inhibition (longer latency to respond).

Two experiments were conducted to examine the phonologic and semantic processing of words, in particular, semantic-related interference in phonologic or semantic processing. A same/different paradigm was used to measure response latencies as a function of phonological or semantic word properties. The stimulus set varied with respect to the phonologic and semantic relationships between pairs of stimuli words. Stimulus word pairs were homonyms, synonyms or unrelated words (with hidden phonologic relationships). Phonologic or semantic judgments (same sound or same meaning) were required of participants. These conditions allowed for comparisons between phonologic and semantic influences in word-identification processes, and further described the influence of automatic and controlled processes. An analysis of word sets that include a simple word that is also a brand name was also performed to test that the response pattern for brand names is the same as non-brand name simple words.

\section{Experiment 1}

\section{Method}

Participants. Twenty-four undergraduates took part in the experiment for course credit. The participants were men and women between 18 and 30 years of age. All were native speakers of English, with normal or corrected-to-normal vision.

Materials. Forty homonym word pairs and their corresponding synonyms formed the stimulus set. Two words were presented simultaneously and the participant was instructed to respond "same" or "different" by pressing a key. There were four conditions varying by the arrangement of homonyms and synonyms. One of the conditions (ID) used the same word twice (e.g., POLL, POLL); this condition served as a baseline. There were three other conditions or pair types: the two words were homonyms (e.g., POLL, POLE), synonyms (e.g., POLE, ROD), or homonyms of synonyms of the target words (POLL - pole - ROD).

Design and Procedure: Two groups of participants, 12 in each group, received either one of the two tasks. One group responded as to whether the words "sound the same"; the other group responded as to whether the words "mean the same." This variable was called "task" (phonologic match and semantic match) and was crossed with "pair type" in a mixed $2 \times 3$ factorial design, with pair type varying within participants and task varying between participants. A phonologic match required participants to indicate whether the words sound the same (ID or homonym pair) or not (synonym and homonym of synonym pairs). A semantic match required "same" responses to ID and synonym pairs and "different" responses to homonym and homonym of synonym pairs. The dependent measure was the time (milliseconds) taken to respond over the baseline condition (ID). Error data was also collected. 
Each session began with 20 practice trials, which were presented in the same order for all participants. Subsequent to the practice trials, 640 experimental trials were presented in random order. The experimental trials were divided into eight blocks of 80 trials, with participants initiating each block. Four blocks of trials were run at a time. A computer connected to a rapid decay display controlled the stimulus presentation and data collection. Participants were tested individually in a single 50-minute session. All participants were instructed to respond as quickly as possible, while avoiding errors. Each trial began with the appearance of the fixation point for two seconds, which was replaced by a stimulus pair. The stimulus remained on the screen until participants responded "same" or "different" by pressing one of two response keys. Pressing one of the two response keys provided immediate feedback. Immediate feedback was provided to the participants after each trial for 500 milliseconds (msec), followed by the reappearance of the fixation point. The total duration of a single trial was 2.5 seconds.

\section{Results}

For all classes of stimuli, mean response times were based on the last four blocks (the latter half of the experimental trials): Asymptotic performance was established through error rates and latencies calculated block by block. Error rates reached asymptote at virtually zero errors by the latter half of trials and are not analyzed further. For each task (phonological match or semantic match), mean response latencies were calculated for each of the word-pair types (homonyms, synonyms and homonyms of synonyms).

In the sound-matching task, neither the synonyms nor homonyms of synonyms produced differences in response time compared to the homonym condition (12 msec average over baseline). It took the same amount of time to respond regardless of the answer, whether it was "same" or "different." Means for each experimental condition are plotted in Figure 1. The semantic relatedness had no effect on response time for sound judgments. However, for the meaning-matching task, responses to homonyms were the fastest (14 msec above baseline); synonyms required $20 \mathrm{msec}$ and homonyms of synonyms to target words required $36 \mathrm{msec}$ longer than baseline response time. This interference caused by the semantic activation of a phonological code is a phonologic-semantic interference, or a "Lexical Stroop Effect." Analysis of variance revealed a significant main effect for pair type $[\mathrm{F}(2,44)=12.01, \mathrm{p}<.001]$. Performance in the phonologic (sound matching) task was the same across pair types. There was no difference in response time for homonym pairs, synonyms, or homonyms' of the synonyms. However, participants assigned to the semantic task showed a response latency increase in the synonym condition over the homonym condition, with the homonym of synonym condition displaying the longest latencies. There was also a significant main effect for task $[\mathrm{F}(1,44)=6.61$, $\mathrm{p}<.025$ ], with a semantic match taking longer than a phonologic match. The interaction was significant $[\mathrm{F}(2,44)=9.71, \mathrm{p}<.001]$, demonstrating the different impact of word-pair type with task. The effect stems from the (hidden) homonym of synonym condition and the long response times relative to baseline associated with this condition $(36 \mathrm{msec})$. Planned comparison of response latencies of synonyms and these seemingly unrelated word-pairs in the meaning matching condition were significant $(\mathrm{p}<.001)$.

\section{Experiment 2}


A second experiment was designed with unrelated words substituted for the homonym of synonym pairs used in Experiment 1. It was hypothesized that the new unrelated pairs would eliminate interference in the "homonym of synonym" condition seen in Experiment 1.

\section{Method}

Participants. A second group of 24 undergraduates took part in the experiment for course credit. The participants were between 18 and 30 years of age and were native speakers of English with normal or corrected-to-normal vision.

Materials. Excluding the third word-pair condition (homonyms of synonyms), the stimuli remained the same as in Experiment 1. The third condition, however, was replaced by matching the 40 target words with unrelated words (e.g., POLL, DOG).

Design and Procedure: The design and procedure were identical to that of Experiment 1. In particular, pair type (homonyms, synonyms and unrelated) was crossed with task type (phonologic match and semantic match) in a $2 \times 3$ factorial design, with pair type varied within participants and task varied between participants. Latency to respond over baseline after pair presentation was again the dependent measure. The apparatus was the same as in Experiment 1.

\section{Results}

Figure 2 illustrates the results of Experiment 2. Results show that the interference associated with the homonyms of synonyms of target words in Experiment 1 disappeared when the words in the pair were totally unrelated. The interaction between pair type and task diminished to marginal significance $(\mathrm{p}<.07)$. Conditions that overlap with Experiment 1 were in close agreement, but the unrelated word pair condition showed no interference. The unrelated word pairs required more time to respond to than the homonym condition but the same amount of response time as the synonyms (20 msec above baseline). This diminished total difference in response latency between the homonym pairs and the combined synonym and unrelated wordpairs is responsible for the diminished interaction. There was a significant main effect for pair type $[\mathrm{F}(2,44)=5.24, \mathrm{p}<.01]$; homonym pairs were responded to more rapidly than synonym and unrelated pairs. The means for the synonym and unrelated conditions were equivalent in planned comparisons of these word-pair types in the same meaning task. There was a main effect for task $[\mathrm{F}(1,44)=5.96, \mathrm{p}<.025]$, again showing that semantic matching took longer than phonetic matching.

\section{Analysis of Brand Name Word Sets}

As a test of the implications for brand names suggested in the introduction of this paper, a set of word pairs that also reflected current brand names (Tide, Nix, Rid) was isolated from the computer generated word sets used for this study and corresponding response latencies were examined. One brand is a well-known leading laundry detergent, while the other two are less known, but leading brands of head-lice shampoo. A set of three brands/simple words was identified across conditions in both Experiment 1 and Experiment 2. Figure 3 shows the mean response times for these words in each condition of Experiment 1 and 2 (e.g. homonym TIED/TIDE, synonym - TIED/KNOT, homonym of a synonym - TIED/WAVE, and unrelated TIDE/HOUSE). As can be seen from Figure 3, the results mimic the pattern of means seen for 
the total set of word-pair types in Experiment 1 and 2. A comparison of these means with a random set of three word pairs drawn from each word-pair condition revealed no significant difference between the brand word pairs and the non-brand word pairs.

\section{Discussion}

\section{The Lexical Stroop Effect}

These experiments demonstrated a "Lexical Stroop Effect." The processing of a comparison word (e.g., POLL) that is a homonym of a synonym (e.g., POLE) of a target word (e.g., ROD) produced interference or response competition that required additional time to resolve. The sound-alike word (e.g., POLE) was automatically activated due to the spreading of the semantic activation. Distinct meanings led to an ambiguous phonologic encoding, biasing a "same" response when a "different" response would be required. When the phonetic relationship (hidden homonym of comparison word is synonym of target word) is removed from the "unrelated" word pair condition, the effect vanishes completely. In this study unrelated words produced response latencies that are virtually identical to the synonym pairs.

Both Experiments 1 and 2 support Hypotheses 1 and 2. The sound-matching task takes less time to respond than the meaning-matching task. Further, homonyms are responded to more quickly than synonyms or unrelated word pairs, but this main effect is almost entirely accounted for by the response time differences for the homonym pairs in the meaning matching condition. Experiment 1 produced the interaction predicted in Hypothesis 3. Although homonyms were responded to more quickly in both the sound matching and the meaning matching conditions, increases in response latencies were found for synonyms and unrelated words only in the meaning matching condition. This interaction was seen in Experiment 1 but was marginally significant in Experiment 2. As can be seen in comparing means in Figure 1 with means in Figure 2, the diminished interaction is due to the unrelated word pairs in Experiment 2. The mean response latencies in Experiment 1 for seemingly unrelated words are greater than the mean response latencies in Experiment 2. Consistent with Hypothesis 4, the automatic competing activation of a homonym of the comparison word that is a synonym of the target word accounts for this additional response latency for (seemingly) unrelated word pairs in Experiment 1.

These results support frameworks offering an indirect path to lexical access via the use of phonologic codes rather than direct orthographic (spelling-to-word identification) access. If the pathway to word representation was direct/orthographic, there would have been no confusion regarding the distinct meaning of the word pairs examined in Experiment 1. These results further suggest that indirect lexical access via phonologic encoding is mediated by semantic processing. This Stroop-like interference effect supports a parallel-processing account of lexical decision making with automatic processing under attentional control. Task orientation to phonetics can limit processing semantically and task orientation to semantics can activate a competing response from phonetic activation. These findings support at least a bi-directional interactive process for phonetic and semantic-level processing in word recognition.

\section{Marketing Implications}

This study shows semantic initiation of response interference from activated phonologic characteristics of otherwise unrelated simple words. This finding suggests that to tap into desired brand associations consumers hold for a market leader, a naming strategy for a brand challenger 
could be to select a word that sounds like a synonym for the extant brand. For example, the brand name "Cares" could be used for a new brand of diapers to be positioned close to the Luvs brand because "Cares" is a synonym of the homophone (loves) of Luvs.

Creating competitive interference is a common strategy in marketing, especially advertising (Burke \& Srull, 1988; Malaviya, Meyers-Levy \& Sternthal, 1999). For example, recent research revealed that repetition of brand claims for a brand in a category comprised of competitors making similar claims can actually increase brand confusion, unless there is strong "binding" between brands and their respective claims (Law, 2002). Similarly, research on brandname recall showed that making a brand name salient or cueing subsets of brands can inhibit recall of other brands within a category (Alba \& Chattopadhyay, 1985; 1986).

The development of an appropriate brand name is a key aspect of branding strategy, and the protection of this name is vital to successful brand management (Keller, 1998; Zaichkowsky, 1995). A new brand (e.g., Rollerblade) in a new product category (e.g., in-line skates) is in the enviable position of creating consumers' schema knowledge about the category; the brand becomes a category "examplar" (Nedungadi \& Hutchinson 1985). One risk in this situation is "genericide" - when the brand name becomes descriptive of the product category in the minds of the consumer and is no longer protected as a trademark that is unique to the producer (Simonson, 1994; Taylor \& Walsh, 2002). Another, more pervasive risk is imitation at both the product form and brand name levels, and the consequent consumer confusion such "me-too" competition creates (Collins-Dodd \& Zaichkowsky 1999; Howard et al, 2000).

For market challengers there are additional issues for branding strategy. Foremost is positioning - whether to position away from or close to extant brands (Dube \& Schmitt, 1999; Sujan \& Bettman, 1989). Among the benefits of positioning closely to a market-leader brand is the ability to tap into favorable brand associations that consumers hold in memory for the leader (Boush, Shipp, Loken, Gencturk, et al, 1987; Keller, 1993). One way to do this is to draw a semantic link from the new brand to the leading brand. However, brand imitation or "passing off" treads legal boundaries. This is especially true if a new brand name is so similar in sound or meaning to the name of the leading brand, consumers become confused as to the brands' respective identities and the sources of the brands (Howard et al, 2000; Leeds, 1956; Wilke \& Zaichkowsky, 1999). Therefore, in order to position close to another brand in terms of the brandname attribute, it is necessary to develop a brand name that would facilitate the automatic activation of links to brand associations attached to a leading brand, while minimizing the deleterious - and possibly illegal - effects of brand confusion. The response latencies reported in this study that result from meaning-based interference are potentially the type of measure of brand confusion demanded by the courts for establishing trademark infringement; however, actually proving consumer confusion and consequent harm to consumers and competition is challenging (Simonson, 1994; Mitchell \& Kearney, 2002).

Nevertheless, the dramatic increase in trademark litigation suggests that companies are becoming ever more vigilant in protecting valued brands (Howard et al, 2000). Businesses invest considerable resources in researching, developing, positioning, marketing and protecting brands. For example, according to one estimate, it costs more than $\$ 2$ million on average to create a brand name for pharmaceutical products (Wick, 2004). A strong brand name is imbued with goodwill, trust, customer knowledge, product-attribute information, and corporate identity (Keller 1993). Zaichkowsky (1995) notes that after price information, brand name is the most used cue for determining customer choice and evaluation. Infringement places this brand equity at risk, in addition to pulling sales from leading brands to imitator brands, which creates a direct 
financial impact (Collins-Dodd \& Zaichowsky 1999; Wilke \& Zaichowsky, 1999). Hence, though product imitators can benefit from associating a new brand with one possessing positive associations in consumer memory, there are risks to the imitation strategy, especially in terms of legal action pursued by brand sponsors desiring to protect their brand name.

The findings in this study suggest that meaning and phonetic-based interference in simple word processing can influence consumer perceptions. However, the controlled experiments performed here sacrificed external validity for internal validity. Indeed, the focus of the task was not brand-name confusion per se, but paired-word comparisons. Furthermore, the comparison task created a high involvement context that may have facilitated lexical interference (Howard et al, 2000). That is, participants were instructed to determine the semantic similarity between words - a task that is uncommon in most real shopping environments, especially those that are typically low involvement (e.g., grocery stores). One area for future research is replication in a more realistic and/or low-involvement context of the experiments performed for this study. Moreover, the suggestion that processing interference in word recognition may facilitate activation of links to target-brand associations deserves research attention. There are many overt examples of same-meaning brand imitation in the marketplace (e.g., Tide and Surf). Concerns about brand confusion wrought by names with similar meanings - or the benefits of such a naming strategy have not been realized, though these remain empirical questions.

\section{Conclusion}

This study provides further evidence of underlying bi-directional, automatic phonologic processing associated with semantic similarities between words. Semantic activation automatically cued phonologic correlates in memory, which in turn produced interference or competing responses in the visual word recognition process. Lexical decision making for even simple words can involve processes that are, in fact, highly complex.

\section{References}

Alba, J. W. \& Chattopadhyay, A. (1985). Effects of context and part-category cues on recall of competing brands. Journal of Marketing Research, 22, 340-349.

Alba, J. W. \& Chattopadhyay, A. (1986). Salience effects in brand recall. Journal of Marketing Research, 23, 363-369.

Baron, J., \& Strawson, C. (1976). Use of orthographic and word-specific knowledge in reading words aloud. Journal of Experimental Psychology: Human Perception and Performance, 4, 207-214.

Bauer, B. \& Besner, D. (1997). Processing in the Stroop task: mental set as a determinant of performance. Canadian Journal of Experimental Psychology, 51, 61-68.

Bell, T. S., \& Wilson, R. H. (2001). Sentence materials controlling word usage and confusability. Journal of the American Academy of Audiology, 12 (10), 514-522. 
Besner, D. \& Stolz, J. A. (1999). What kind of attention modulates the Stroop Effect? Psychonomic Bulletin and Review, 6, 99-104.

Besner, D., Stolz, J. A. \& Boutilier, C. (1997). The Stroop effect and the myth of automaticity, Psychonomic Bulletin and Review, 3 (2), 221-225.

Besner, D. \& MacNevin, C. (2002). When are morphemic and semantic priming observed in visual word recognition? Canadian Journal of Experimental Psychology,56 (2), 112-119.

Borowsky, R., \& Owen, W. J., (2003). Examining the interactivity of lexical, orthographic and and phonological processing. Canadian Journal of Experimental Psychology, 57 (4), 290303.

Borowsky, R., Owen, W. J., \& Fonos, N. (1989). Reading speech and hearing print: constraining models of visual word recognition by exploring connections with speech perception. Canadian Journal of Experimental Psychology, 53, 294-305.

Boush, D., Shipp, S., Loken, B., Gencturk, E., Crockett, S., Kennedy, E., Minshall, B., Misurell, D., Rochford, L. \& Strobel, J. (1987). Consumer Behavior Seminar--Affect generalization to similar and dissimilar brand extensions. Psychology \& Marketing, 4 (3), 225-237.

Bradshaw, J. L (1975). Three interrelated problems in reading: a review. Memory \& Cognition, $3,123-134$.

Bradshaw, J. L., \& Nettleton, N. C. (1974). Articulatory interference and the mown-down heterophone effect. Journal of Experimental Psychology, 102, 88-94.

Burke, R. R., \& Srull. T. K. (1988). Competitive interference and consumer memory for advertising. Journal of Consumer Research, 15 (1), 55-68.

BusinessWeek (2003). The best global brands: 2003 global brands scoreboard. (August 4), 7278.

Cohen, J. D., Dunbar, K., \& McClelland, J. L. (1990). On the control of automatic processes: a parallel distributed processing account of the Stroop Effect. Psychological Review, 97(3), 332-361.

Collins-Dodd, C., \& Zaichkowsky, J. L. (1999). National brand responses to brand imitation: retailers versus other manufacturers. The Journal of Product and Brand Management, 8 (2), 96-108.

Coltheart, V., Laxon, V., Rickard, M., \& Elton, C. (1988). Phonological recoding in reading for meaning by adults and children. Journal of Experimental Psychology: Learning, Memory, and Cognition, 14 (3), 387-397. 
Coltheart, M. Rastle, K., Perry, C., Langdon, R. \& Zeigler, J. (2001). DRC: A dual route cascade model of visual word recognition and reading aloud. Psychological Review, 108, 204-256.

Doctor, E. A., \& Coltheart M. (1980). Children's use of phonological encoding when reading for meaning. Memory and Cognition, 8, 195-209.

Dube, L., \& Schmitt, B. H. (1999). The effect of a similarity versus dissimilarity focus in positioning strategy: the moderating role of consumer familiarity and product category. Psychology \& Marketing, 16 (3), 211-223.

Goldinger, S., Luce, P. \& Pisoni, D. (1989). Priming lexical neighbors of spoken words: effects of competition and inhibition. Journal of Memory and Language, 29, 501-519.

Hardyck, C. D., \& Petrinovitch, L. R. (1970). Subvocal speech and comprehension level as a function of the difficulty level of reading material. Journal of Visual Learning and Verbal Behavior, 9, 647-652.

Howard, D. J., Kerin R. A., \& C. Gengler (2000). The effects of brand name similarity on brand source confusion: implications for trademark infringement. Journal of Public Policy \& Marketing, 19 (2), 250-264.

Humphreys, G. W., Everett, L. J., \& Taylor. D. E. (1982). Automatic phonological priming in visual word recognition. Memory \& Cognition, 10(6), 576-590.

Jacobs, A. M., Rey, A., Zeigler, J. C., \& Grainger, J. (1998). MROM-P: An interactive activation, multiple read-out model of orthographic and phonological processes in visual word recognition. In J. Grainger \& A. M. Jacobs (Eds.), Localist connectionist approaches to human cognition (pp. 147-188). Mahwah, ND: Erbaum.

Jacoby, J. \& Morrin, M (1998). Not manufactured or authorized by ...”: recent federal cases involving trademark disclaimers. Journal of Public Policy \& Marketing, 17 (1), 97-107.

Keller, K. L. (1993). Conceptualizing, measuring, and managing customer-based brand equity. Journal of Marketing, 57 (January), 1-22.

Keller, K. L. (1998). Strategic brand management: building, measuring, and managing brand equity. Upper Saddle River, NJ: Prentice Hall.

Kotler, P., \& Armstrong, G (2004). Principles of marketing, $10^{\text {th }}$ Ed. Upper Saddle River, NJ: Prentice Hall.

Law, S. (2002). Can repeating a brand claim lead to memory confusion? The effects of claim similarity and concurrent repetition. Journal of Marketing Research, 39, 366-378.

Leeds, D. (1956). Confusion and consumer psychology. The Trademark Reporter, 46, 108-114. 
Martin, M. (1978). Speech recoding in silent reading. Memory \& Cognition, 6, 108-114.

Malaviya, P., Meyers-Levy, J., \& Sternthal, B. (1999). Ad repetition in a cluttered environment: The influence of type of process. Psychology \& Marketing, 16 (2), 99-118.

McClelland, J. L., \& Rumelhart, D. E. (1981). An interactive model of context effects in letter perception: Part 1, An account of basic findings, Psychological Review, 88, 375-407.

McNamara, T. P., \& Healy, A. F. (1988). Semantic, phonological, and mediated priming in reading and lexical decisions. Journal of Experimental Psychology: Learning, Memory and Cognition, 14, (3), 398-409.

Mitchell, V-P., \& Kearney, I. (2002). A critique of legal measures of brand confusion. Journal of Product and Brand Management, 11 (6), 357-379.

Naish, P. (1980). Phonological recoding and the Stroop effect. British Journal of Psychology, $71,395-400$.

Nedungadi, P. \& Hutchinson W. (1985). The prototypicality of brands: relationships with brand awareness, preference, and usage. in Advances in Consumer Research, 12, E. C. Hirschman and M. B. Holbrook, eds. Provo, UT: Association for Consumer Research, 489-503.

Posner, M. I. \& Keele, S. W. (1967). Decay of visual information from a single letter. Science $158,137-139$.

Seidenberg, M. S. \& McClelland, J. L. (1989). A distributed, developmental model of word recognition and naming. Psychological Review, 96 (4), 523-568.

Simonson, I. (1994). Trademark infringement from the buyer perspective: conceptual analysis and measurement implications. Journal of Public Policy \& Marketing, 13 (2), 181-199.

Stroop, J. R. (1935). Studies of interference in serial verbal reactions. Journal of Experimental Psychology, 18, 643-661.

Sujan, M. \& Bettman, J. R. (1989). The effects of brand positioning strategies on consumers' brand and category perceptions: Some insights from schema research. Journal of Marketing Research, 26, 454-467.

Taylor, C. R. \& Walsh, M. G. (2002). Legal strategies for protecting brands from genericide: Recent trends in evidence weighted in court cases. Journal of Public Policy \& Marketing, 21 (1), 160-167.

Van Orden, G. W. (1987). A ROWS is a Rose: Spelling, sound and reading. Memory \& Cognition, 15, 181-198. 
Van Orden, G. W., Johnston, J. C., \& Hale, B.L (1988). Word identification in reading proceeds from spelling to sound to meaning. Journal of Experimental Psychology: Learning, Memory and Cognition, 14(3), 371-386.

Wagner, R. K. \& Torgeson, J. L. (1987). The nature of phonological processing and its casual role in the acquisition of reading skills, Psychological Bulletin, 101,192-212.

Wick, J (2004). What's in a drug name? Journal of the American Pharmacists Association, 44 (1), 12-14.

Wilke R. \& Zaichkowsky J. L. (1999). Brand imitation and its effects on innovation, competition, and brand equity. Business Horizons, (Nov./Dec.), 9-18.

Yorkston, E. \& Menon, G. (2004). A sound idea: phonetic effects of brand names on consumer judgments. Journal of Consumer Research, 31(1), 43-51.

Zaichkowsky, J. L. (1995). Defending your brand against imitation. Westport, CN: Greenwood Publishing Group, Inc. 


\section{Author Notes}

Judith E. Hennessey, Department of Marketing, California State University, Northridge; Theodore Bell is at Department of Psychology, California State University, Los Angeles. Robert Kwortnik is at the School of Hotel Administration, Cornell University. Each author contributed equally to this article.

The authors would like to thank David Pisoni and James Craig, at the Department of Psychology, Indiana University, for the use of their laboratories in the development of stimuli. The authors would also like to thank Roger Rhodes, at the Department of Psychology, Indiana University, for his assistance in the initial instrumentation and data collection for this study. The authors would also like to thank Leon Kaspersky for his help in instrumentation of these experiments and Claudia Garcia for her assistance in data analysis and presentation.

Part of the data used in developing this study was presented at the Western Decision Science Institute Conference, Waikiloa, Hawaii, 1998.

Correspondence concerning this article should be addressed to Judith Hennessey, Department of Marketing, California State University, Northridge, Northridge, California 913308377. Email: judith.hennessey@ csun.edu. 
Lexical Interference 19
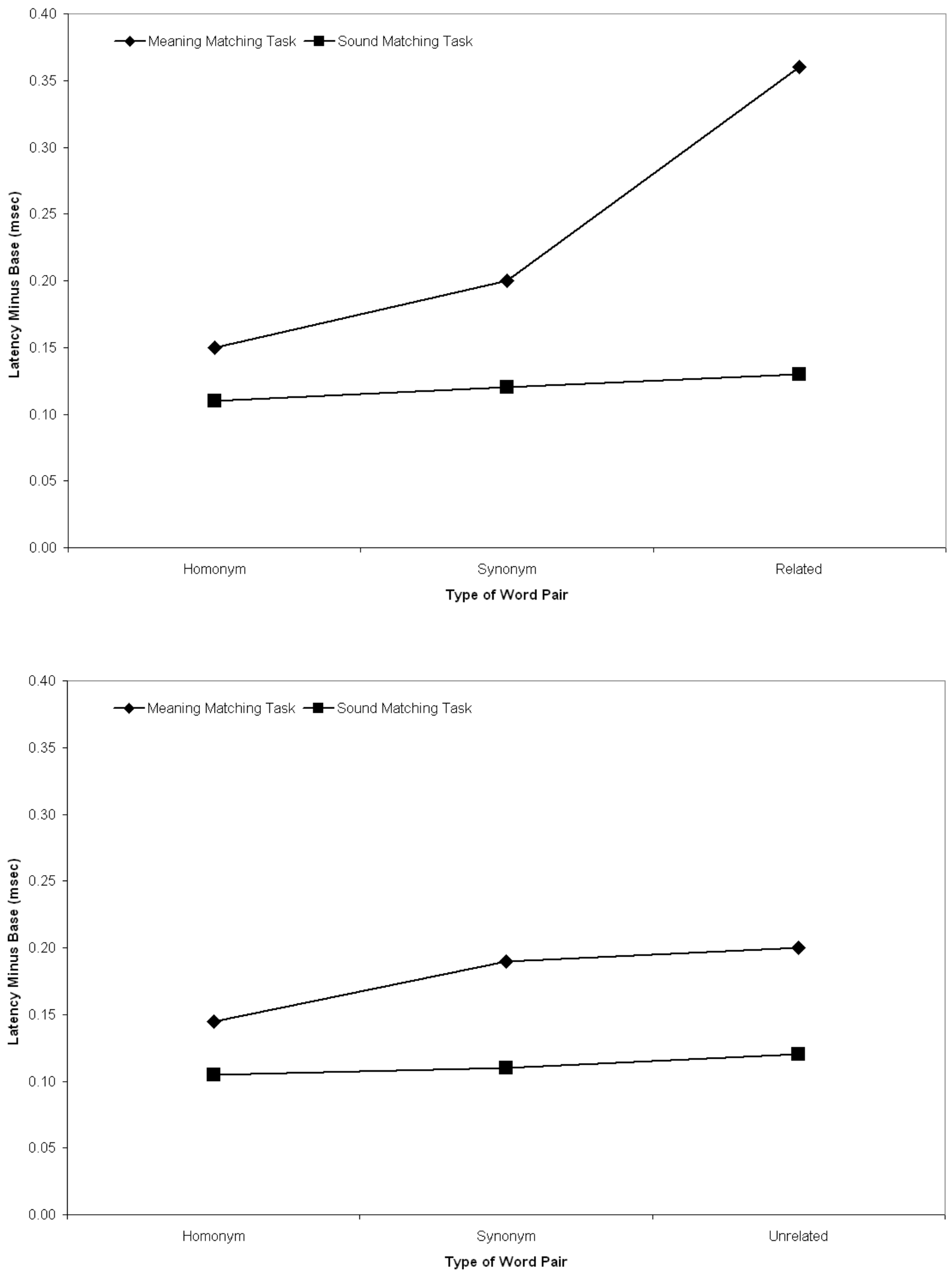
Lexical Interference 20

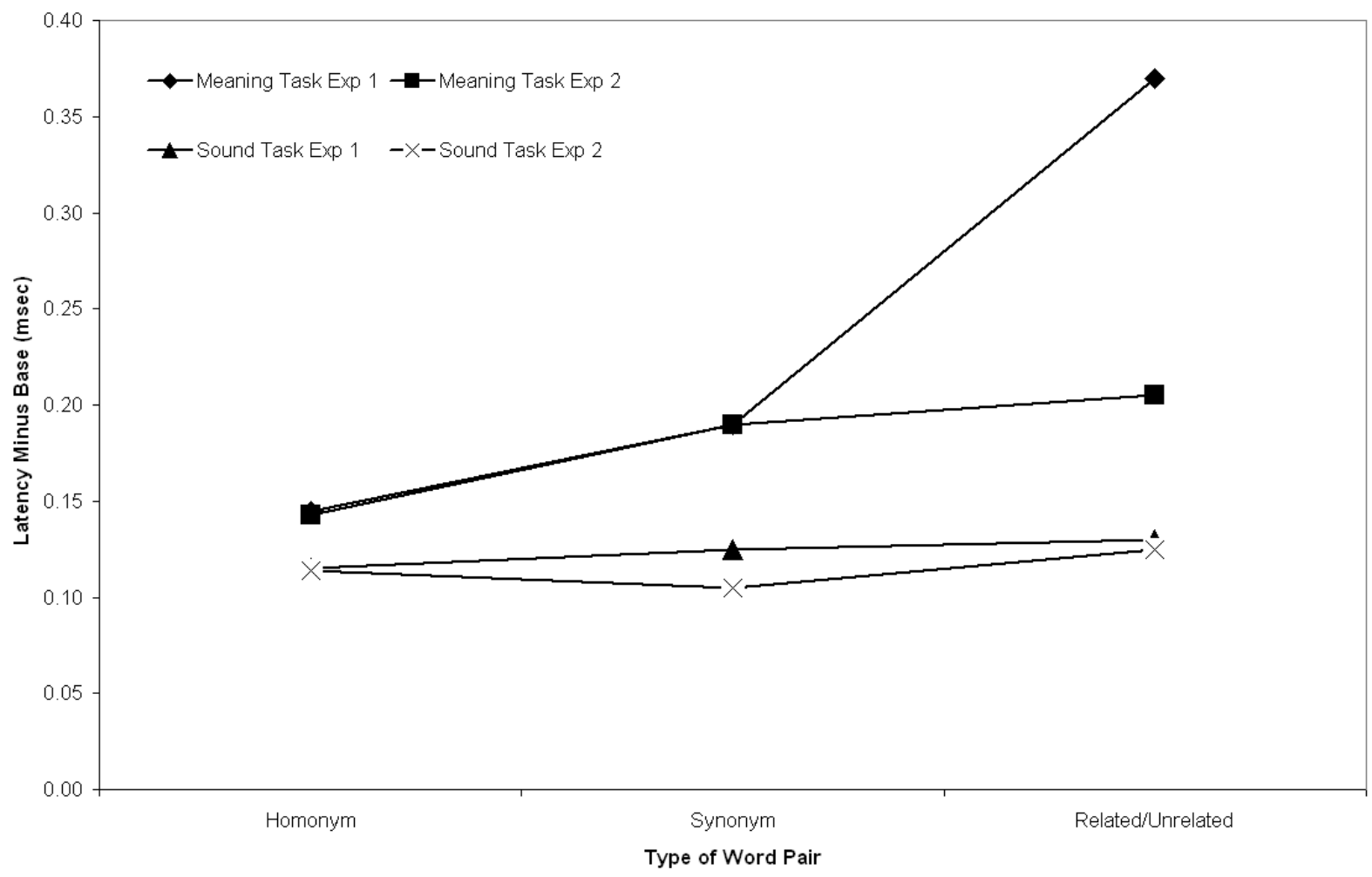

